STRABISMUS AND OCULAR

MOTILITY DISORDERS 


\title{
STRABISMUS AND OCULAR MOTILITY DISORDERS
}

\author{
Proceedings of the Sixth Meeting of the International \\ Strabismological Association \\ Surfers Paradise, Australia, 1990
}

\section{Edited by}

Emilio C. Campos

Department of Ophthalmology

University of Modena

Modena, Italy

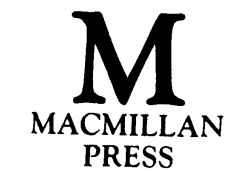

Scientific \& Medical 
(C) The Macmillan Press Ltd 1990

Softcover reprint of the hardcover 1st edition 1990 978-0-333-51224-1

All rights reserved. No reproduction, copy or transmission of this publication may be made without written permission.

No paragraph of this publication may be reproduced, copied or transmitted save with written permission or in accordance with the provisions of the Copyright, Designs and Patents Act 1988, or under the terms of any licence permitting limited copying issued by the Copyright Licensing Agency, 33-4 Alfred Place, London WC1E 7DP

Any person who does any unauthorized act in relation to this publication may be liable to criminal prosecution and civil claims for damages.

First published 1991

Published by

THE MACMILLAN PRESS LTD

Houndmills, Basingstoke, Hampshire RG21 2XS

and London

Companies and representatives

throughout the world

British Library Cataloguing in Publication Data

International Strabismological Association

Meeting (6th 1990: Surfers Paradise, Australia)

Strabismus and motility disorders.

1. Man. Eyes. Movement disorders \& strabismus

I. Title II. Campos, E. C. (Emilio C.)

617.762

ISBN 978-1-349-11190-9 ISBN 978-1-349-11188-6 (eBook)

DOI 10.1007/978-1-349-11188-6 


\title{
CONTENTS
}

\author{
Preface xiii \\ Acknowledgements xv \\ The Contributors $x v i$ \\ THE LINKSZ AWARD AND MEDAL $x x v i$ \\ Introduction of the Recipient of the Linksz
Award and Medal: Elfriede Aulhorn Gunter K. von Noorden \\ OBITUARIES \\ Thomas Keith Lyle Kenneth Wybar $\quad x x x$ \\ Arthur Linksz Gunter K. von Noorden xxxiv \\ Charles Thomas Annette Spielmann xxxv \\ Tunekazu Yuge Shinobu Awaya xxxvii \\ THE SIXTH BIELSCHOWSKY LECTURE 1 \\ Introduction of the 1990 Bielschowsky Lecturer
Gunter K. von Noorden \\ The Sixth Bielschowsky Lecture: Control of Eye Vergence
and Anomalous Retinal Correspondence Peter O. Bishop
}

Part I. Amblyopia and Development of Visual Function

1. Amblyopia: Correlation between Human and Animal Research G. K. von Noorden

2. Amblyopia in Old People and Residual Amblyopia in Children: Prevalence before and after Free Visual Acuity Screening and Occlusion

Treatment

E. Gregersen, A. Jensen, E. Rindziunski and

T. Vinding

3. Amblyopia: Care and Prevalence in Pre-school

Children, Campinas, São Paulo, Brazil

K. M. Monteiro de Carvalho, N. Kara-Jose,

R. Caldato, A. M. Oliveira, J. Fonseca Neto and V. L. Pereira

4. The Incidence of Amblyopia in Longstanding

Untreated Infantile Esotropia

A. D. N. Murray and C. Calcutt 
5. Comparison of Treatment Methods in Strabismic Amblyopia R. M. L. Doran, S. Yarde and A. Starbuck

6. Amblyopia, Strabismus and Anisometropia in Congenital Glaucoma Patients L. M. Christmann and J. G. Ferguson, Jr

7. A Trial of P-ERG for the Aid of Therapy in Amblyopia S. Takayama, K. Nomura, K. Fujioka, T. Shinkai and M. Yamamoto

8. Retinal Sensitivity in Amblyopia Cases M. Ito, M. Imaizumi, H. Miyazawa and M. Yamamoto

9. Pattern VEP and Accommodation in Anisometropic Amblyopia T. Ohzeki

10. Observations on Grating Acuity Measures of Children in Clinical Practice Using Teller Acuity Cards A. Chandna and R. M. L. Doran

11. Development of Visual Acuity Tested by Grating Acuity Cards in Pre-term and Full-term Newborn and Premature Infants Y. Tsukita, H. Mitani, H. Miyazawa and M. Yamamoto

12. Visual and Ocular Motor Assessment of Infants:

A Preliminary Report L. McKenzie

Part II. Binocular Vision

13. Studies of Stereoacuity in Infants by the TV-Random Dot Stereo Test S. Awaya, Y. Mizukami, A. Kamiya, E. Koizumi and S. Miyake

14. Clinical Applications of Stereograms Made with IBM Microcomputer L. L. $-K$. Lin, S. F. Wu, J.-H. Jan and A.-H. Wang

15. Evaluation of Lang's Test as a Screening Procedure in Children L. A. Peduti-Cunha and J. A. F. Caldeira

16. Influence of Vertical Fusion on Horizontal Fusion W. Aust

17. Binocular Dissociation by the Mechanism of Time Separation A.-H. Wang, J.-H. Jan, J.-H. Yu, L. L. - K. Lin and L. $-S$. Ko 
Part III. Investigations and Measurements

18. The Observation of Eye Movement Using Magnetic Resonance Imaging Y. Nishida, E. Nishida,

$K$. Kani and A. Inatomi

19. Dynamic Analysis of Head Movements by Means of a Three-dimensional Position Measurement System Y. Watanabe, H. Ohtsuki, H. Okayama, H. Konishi, Y. Fujiwara, S. Hasebe and M. Takeda

20. A Clinical Method of Measuring the CA/C Ratio I. Strachan and $M$. Watts

21. Photographic Measurement of the Angle of Strabismus M.S. Ruttum, K. Shimshak and M. Chesner

22. The Use of the Corneal Reflex Test through Glasses Y. Hatsukawa, T. Otori, B. Patel, C. Hogg and P. Fells

23. Squint Surgery Performed with Measurement of the Globe by A-Scan Compared with Standard Surgery W. E. Gillies and A.M. V. Brooks

24. A Method for Determining Intraoperative Length-Tension Curves of Human Extraocular Muscles

J. E. Egbert, A. L. Rosenbaum, T. M. Keogan Jr, N. C. Wheeler, K. A. Buzard and C. Wang

25. A Right-angle Siamese-twin Caliper for Greater Accuracy and Precision in Eye Muscle Surgery P. E. Romano and C. E. Hess

26. Application of the Computer in Strabismology J.-H. Jan, L. L. -K. Lin, A.-H. Wang and Y.-F. Shih

27. Polaroid Photorefractive Screening for Amblyopia H. L. Freedman and K. L. Preston

28. A New Dot Visual Acuity Test for Children H. Morizane and K. Morizane

29. Event-related Potentials in Disturbance of Vision of Psychogenic Origin Y.Oguchi

Part IV. Special Forms of Strabismus

30. Pathophysiology of the Symptoms of Infantile Strabismus A.Spielmann 
31. Origin of the Lateral Rectus Paresis in Strabismus of High Myopic Patients B. Bagolini, A. Dickmann, C. Tamburrelli and C. Colosimo

32. Duane's Retraction Syndrome: A Review of 72 Cases F. J. Martin and K. M. Bourne

33. Further Insights into Developmental Errors Causing Duane's Syndrome M. T. Miller and $K$. Stromland

34. Two Mechanisms of Up-shoots and Down-shoots in Duane's Syndrome Revealed by a new MRI Technique J. M. Miller, J. L. Demer and A. L. Rosenbaum

35. Strabismus Resulting from Retinal Detachment Surgery: Some aspects of Management A. F. Hilton

\section{Part V. Nystagmus}

36. Oscillopsia in Congenital Nystagmus

L. A. Abel, I. M. Williams and L. Levi

37. Treatable Nystagmus (Manifest Latent Nystagmus)

R. D. Reinecke and A. A. Zubcov

38. Results of Horizontal Rectus Muscle Surgery to Modify the Null Point in Congenital Nystagmus J. A. Pratt-Johnson

39. Compensation Mechanisms and Treatment in Nystagmus Patients with Albinism or Congenital Cataract $H$. Mühlendyck

\section{Part VI. Esotropia}

40. Symposium on the Management of Fully Accommodative Esotropia Moderator: P. Fells

Speakers: P. V. Berard, M. Gobin, A. Jampolsky, A. C. B. Molteno, G. K. von Noorden, C. Schor and M. Spiritus

41. Outcome of Accommodative Esotropia

T. Nakagawa, T. Kii and S. Mori

42. Long-term Follow-up of Refractive Accommodative Esotropia N. Kubota and S. Akatsu 
43. The Accommodative Component after Esotropia Surgery E. L. Raab

44. 'Ultra-early' Surgery for Essential Infantile Esotropia E. M. Helveston

45. Late Management of Infantile Esotropia A. A. Assaf

46. Stability of the Monofixation Syndrome B. W. Arthur, J. T. Smith and W. E. Scott

47. Clinical Characterstics of Non-accommodative Intermittent Esotropia $S$. Akatsu, H. Iwashige, N. Kubota and T. Maruo

48. Defining the Limits of Safe Recession of the Horizontal Recti Muscles A. M. V. Brooks, M. R. Rivers, N. T. Strang and W. E. Gillies

\section{Part VII. Exotropia}

49. Outcome of Early Overcorrection of Exotropia E. L. Raab

50. Binocularity after Surgery for Intermittent

Exotropia S. M. Wolff and D. N. Loupe

51. Surgical Alignment for Exotropia in Children M. R. Ing

52. Atypical Cyclic Exotropia Y. Uemura, N. Nozaki and R. Yamada

53. Differential Resection of Medial Recti in Convergence Insufficiency $P$. Nemet and C. Stolovitch

54. Survey of Current Management of Intermittent Exotropia in the USA and Canada $P$. E. Romano and $M . F$. Wilson

55. Treatment of Exotropia with Gasserian Ganglion Block $O$. Tamura and $M$. Abe

\section{Part VIII. Botulinum Toxin in Strabismus}

56. Botulinum Toxin Treatment of Strabismus A. B. Scott 
57. Botulinum Treatment of Childhood Strabismus A. B. Scott, E. H. Magoon, K. W. McNeer and D. R. Stager

58. The Physiology of Botulinum Toxin J.S. Elston

59. Botulinum Toxin: an Alternative to Squint Surgery in Childhood? S. Hague and J. P. Lee

60. The Histopathology of Botulinum Toxin Injection into Extraocular Muscles $K$. W. McNeer and R. F. Spencer

61. Botulinum Toxin for Restrictive Strabismus J. Lee

62. A Discussion of the Current Role of Botulinum Toxin in Paralytic Strabismus R. Fitzsimons

Part IX. Surgery

63. Lateral Rectus Muscle Transplantation Surgery for Third Nerve Palsy J. Norton Taylor

64. Anterior Ciliary Vessel Preservation During Rectus Muscle Surgery C.A. McKeown, H. M. Lambert and J. W. Shore

65. Personal Approach for Adjustable Sutures Technique E. C. Campos, C. Chiesi, $R$. Gulli and C. Schiavi

66. Post-operative Drift Following Adjustable Strabismus Surgery J. Lee, P. Rosen, R. Morris, B. McCarry and P. Fells

67. Results of Stage III Intraoperative Adjustment of Eye Muscle Surgery (under General Anesthesia) for Neuroparalytic and Mechanical Strabismus P. E. Romano

68. Superior Oblique Silicone Expander for Brown's Syndrome and Superior Oblique Overaction K. W. Wright

69. Desagitalization of the Superior Rectus:

A Simple Method to Correct Abnormal Head Posture in Congenital Absence of the Superior Oblique S. Miyake, K. Tsuzuki, T. Yagasaki and S. Awaya 
70. A Study of Horizontal Strabismus Surgery:

Is Medial Rectus Surgery More Effective on Near Deviation? M. Deguchi, T. Yokoyama,

K. Kamihata, Y. Matsuzaka, K. Kawanami,

S. Hosoi and H. Tanaka

71. Overnight Admission of Outpatient Strabismus

Patients S. J. Isenberg, L. Apt and S. Yamada

Part X. Miscellaneous

72. Neurological Correlates to Strabismus and other Ocular Motility Disturbances in Meningomyelocele G. Lennerstrand and L. Samuelsson

73. Ocular Motility Defects in Motor Neurone Disease I. M. Williams, L. A. Abel and K. G. Gibson

74. The Effect of Radiotherapy on Abnormal Eye Movements in Dysthyroid Orbitopathy

J. S. Elston and P. N. Plowman

75. Oculomotor Problems Associated with the Blepharophimosis Syndrome J. W. Walker and R. Collins

76. Blowout Fractures Combined with Isolated Laceration of Rectus Muscles $C$. Stolovitch, $P$. Nemet and M. Lazar

77. Ocular Morbidity in Extremely Low Birth Weight Infants C. G. Keith, L. W. Doyle and W. H. Kitchen

Index 


\section{PREFACE}

This book is the collection of papers presented at the sixth Congress of the International Strabismological Association (I.S.A.) which took place from March 11 th to 16 th, 1990 at Surfers Paradise, Queensland, Australia. The meeting was under the Chairmanship of the I.S.A. President Gunter K. von Noorden. A Local Committee, chaired by Bill Gillies, provided an impeccable organization of every detail and made the Congress and the stay in Australia a memorable experience for all the participants.

There was a good attendance and many countries were actively represented. The Program Committee chaired by Peter Fells did an excellent job in providing many stimulating scientific sessions. Around 75 papers and posters were presented. The majority of them are published in this book. I am grateful to the authors for having accurately prepared their papers according to our request and for having provided them in due time in order to be able to have the book ready in a reasonably short time and thus serve the reader with an up-to-date and "fresh" product. I have also included the abstracts of those papers the manuscripts of which were missing, in order to have a proceedings volume as complete as possible.

The English used in this book may show some minor or major pitfalls, as it is not the native language of many authors. I believe, however, that this is a positive element because it shows the effort made by all our colleagues to use a common denominator to allow the international spread of their contributions. Some papers have had to be rewritten by the Editor.

One of the highlights of the Congress was a round table on the treatment of refractive accommodative esotropia. A transcript of this round table appears in this volume, thanks to the friendly cooperation of the moderator and the panelists. 
With the preparation of this proceedings volume I end my office of Editor. I thank the I.S.A. Council and Membership for their support and confidence. I am particularly pleased by the fact that Macmillan Press has accepted to be our Publisher.

Emilio C. Campos Modena, May 1990 


\section{ACKNOWLEDGEMENTS}

The preparation of this Proceedings Volume required the help of many people whose work I gratefully acknowledge. My secretary, Ms. Paola Santini provided invaluable help at many stages, including the preparation of the index and the list of contributors. $\mathrm{Mr}$. John M. Pradelli has to be thanked for his editorial help and the tedious work of recombination needed for the transcript of the round table. Thanks are due also to the Publisher, Macmillan Press and particularly to $\mathrm{Mr}$. David Grist for his understanding and cooperation. 


\section{THE CONTRIBUTORS}

\author{
M. ABE \\ Dept. of Ophthalmology \\ Eihme University \\ Eihme, Japan
}

\section{L.A. ABEL}

Dept. of Biomedical Eng.

Akron University

Akron, U.S.A.

\section{S. AKATSU}

Dept. of Ophthalmology

Teikyo University

Tokyo, Japan

\section{APT}

Dept. of Ophthalmology

U.C.L.A. School of Medicine Los Angeles, U.S.A.

B.W. ARTHUR

Dept. of Ophthalmology Queen's University

Kingston, Canada

\section{A.A. ASSAF}

Dept. of Ophthalmology

King Saud University

Riyadh, Saudi Arabia

W. AUST

Eye Clinic

Kassel Teaching Hospital

Kassel, W. Germany

\section{S. AWAYA}

Dept. of Ophthalmology

Nagoya University

Nagoya, Japan

\section{B. BAGOLINI}

Dept. of Ophthalmology

Catholic University

Rome, Italy

\author{
P.V. BERARD \\ "Atalante" \\ 397 Corniche Kennedy \\ Marseille, France \\ P.O. BISHOP \\ Dept. of Anatomy \\ University of Sydney \\ Sydney, Australia \\ K. M. BOURNE \\ The Children's Hospital \\ Camperdown, Australia
}

\section{A.M.V. BROOKS}

Royal Victorian

Eye and Ear Hospital

Melbourne, Australia

K.A. BUZARD

Dept. of Ophthalmology

UCIAA School of Medicine

Los Angeles, California

\section{CALCUTT}

Dept. of Ophthalmology

Charing Cross Hospital

London, U.K.

J.A.F . CALDEIRA

Dept. of Ophthalmology University of Sao Paulo

Sao Paulo, Brazil

\section{R. CALDATO}

Dept. of Ophthalmology

State University of Campinas

Sao Paulo, Brazil

E.C. CAMPOS

Dept. of Ophthalmology

University of Modena

Modena, Italy

xvi 


\section{A. CHANDNA}

Bristol Eye Hospital

Bristol, U.K.

M. CHESNER

Dept. of Ophthalmology The Medical College of Wisconsin

Milwaukee, U.S.A.

C. CHIESI

Dept. of Ophthalmology University of Modena

Modena, Italy

L.M. CHRISTMANN

Dept. of Ophthalmology

University of South

Carolina

Columbia, U.S.A.

R. COLLINS

The Hospital for

Sick Children

Moorfield Eye Hospital

London, U.K.

C. COLOSIMO

Dept. of Radiology

Catholic University

Rome, Italy

M. DEGUCHI

Dept. of Ophthalmology

Osaka City University

Medical School

Osaka, Japan

J.L. DEMER

Jules Stein Eye Institute and Dept. of Neurology UCLA Center for the

Health Sciences

Los Angeles, U.S.A.
A. DICKMANN
Dept. of Ophthalmology
Catholic University
Rome, Italy

R.M.L. DORAN

General Infirmary

Leeds, U.K.

L.W. DOYLE

Dept. of Pediatrics

The Royal Women's Hospital

Melbourne, Australia

J.E. EGBERT

Dept. of Ophthalmology

UCLA School of Medicine

Los Angeles, U.S.A.

J.S. ELSTON

The National Hospital

for Nervous Diseases

Queen Square

London, U.K.

P. FELLS

Moorfields Eye Hospital

London, U.K.

\section{J.C. FERGUSON}

Dept. of Ophthalmology

University of South Carolina

Columbia, U.S.A.

R. FITZSIMONS

1606/187 Liverpool Street

Sydney, Australia

J. FONSECA NETO

Dept. of Ophthalmology

State University of Campinas

Sao Paulo, Brazil

H.L. FREEDMAN

Dept. of Ophthalmology

University of Washington

Washington, U.S.A. 
xviii

Y. FUJIWARA

Dept. of Ophthalmology

Okayama University

Okayama-shi, Japan

K. FUJIOKA

Dept of Ophthalmology

Kobe Children's Hospital

Kobe, Japan

K.G. GIBSON

Neuro-Ophthalmology

Laboratory

Monash University

Melbourne, Australia

W.E. GILLIES

Royal Victorian

Eye and Ear Hospital

Melbourne, Australia

M. GOBIN

Dept. of Ophthalmology

University of Leiden

Leiden, Belgium

E. GREGERSEN

University Eye Clinic

Rigshospitalet

Copenhagen, Denmark

R. GULLI

Dept of Ophthalmology

University of Modena

Modena, Italy

S. HAGUE

Moorfields Eye Hospital

City Road

London, U.K.

S. HASEBE

Dept. of Ophthalmology

Okayama University

Okayama-shi, Japan
THE CONTRIBUTORS

Y. HATSUKAWA

Dept. of Ophthalmology

Kinki University

School of Medicine

Osaka, Japan

E.M. HELVESTON

Pediatric Ophthalmology

Indiana University

Indianapolis, U.S.A.

C.E. HESS

Gainesville, U.S.A.

A.F. HILTON

Princess Alexandra Hospital

Brisbane, Australia

C. HOGG

Moorfields Eye Hospital

London, U.K.

S. HOSOI

Dept. of Ophthalmology

Osaka City University

Medical School

Osaka, Japan

M. IMAIZUMI

Dept of Ophthalmology

Kobe University

Kobe, Japan

A. INATOMI

Dept. of Ophthalmology

Shiga University

Otsu, Japan

$M . R$. ING

Dept. of Ophthalmology

John A. Burns School

Medicine, Hawaii University

Honolulu, U.S.A. 
S.J. ISENBERG

Dept. of Ophthalmology UCLA School of Medicine Los Angeles, U.S.A.

M. ITO

Dept. of Ophthalmology

Kobe University

Kobe, Japan

H. IWASHIGE

Dept. of Ophthalmology

Teikyo University

Tokyo, Japan

\section{A. JAMPOLSKY}

Smith Kettlewell Eye

Research

2232 Webster Street

San Francisco, U.S.A.

$\mathrm{J}-\mathrm{H}$. JAN

Dept. of Ophthalmology

National Taiwan University

Taipei, Taiwan

\section{A. JENSEN}

University Eye Clinic

Rigshospitalet

Copenhagen, Denmark

A. KAMIYA

Dept. of Ophthalmology

Nagoya University

Nagoya, Japan

\section{K. KAMIHATA}

Dept. of Ophthalmology

Osaka City University

Osaka, Japan

K. KANI

Dept. of Ophthalmology

Shiga University

Otsu, Japan
J.N. KARA

Dept. of Ophthalmology

State University of Campinas

Sao Paulo, Brazil

K. KAWANAMI

Dept. of Ophthalmology

Osaka City University

Medical School

Osaka, Japan

C.G. KEITH

231 Flemington Road

Melbourne, Australia

T.M. KEOGAN

Dept. of Biomathematics UCLA School of Medicine

Los Angeles, U.S.A.

T. KII

Dept. of Ophthalmology

Sapporo Medical College

Sapporo, Japan

W.M. KITCHEN

Dept. of Pediatrics

The Royal Women's Hospital

Melbourne, Australia

L-S. KO

Dept. of Ophthalmology

National Taiwan University

Taipei, Taiwan

E. KOIZUMI

Dept. of Ophthalmology

Nagoya University

Nagoya, Japan

H. KONISHI

Dept. of Ophthalmology

Okayama University

Okayama-shi, Japan 
N. KUBOTA

Dept. of Ophthalmology Teikyo University

Tokyo, Japan

H.M. LAMBERT

Dept. of Ophthalmology

Emory University

Atlanta, U.S.A.

M. LAZAR

Dept. of Ophthalmology

Tel Aviv University

Medical Center

Tel Aviv, Israel

J.P. LEE

Moorfields Eye Hospital

City Road

London, U.K.

G. LENNERSTRAND

Dep. of Ophthalmology

Karolinska Institute

Stockholm, Sweden

L. LEVI

Neuro-Ophthalmology

Laboratory

Monash University

Melbourne, Australia

L.L-K. LIN

Dept. of Ophthalmology

National Taiwan University

Taipei, Taiwan

D.N. LOUPE

Wilmer Institute

The Johns Hopkins

University

Baltimore, U.S.A.

E.H. MAGOON

Dept. of Ophthalmology

N.E. Ohio College of

Medicine

Canton, U.S.A.
F.J. MARTIN

The Children's Hospital

Camperdown, Australia

T. MARUO

Dept. of Ophthalmology

Teikyo University

Tokyo, Japan

Y. MATSUZAKA

Dept. of Ophthalmology

Osaka City University

Osaka, Japan

B. MCCARRY

Moorfields Eye Hospital

London, U.K.

L. MCKENZIE

Division of Orthoptics

La Trobe University

Melbourne, Australia

C.A. MCKEOWN

Dept. of Ophthalmology

One Clinic Center

Cleveland, U.S.A.

K.W. MCNEER

Dept. of Ophthalmology

Medical College of Virginia

Richmond, U.S.A.

J.M. MILLER

Smith Kettlewell Eye

Research

2232 Webster street

San Francisco, U.S.A.

M.T. MILLER

Dept. of Ophthalmology

University of Illinois

Chicago, U.S.A. 
M. MITANI

Dept. of Ophthalmology

Kobe University

Kobe, Japan

Y. MIZUKAMI

Dept. of Ophthalmology Nagoya University

Nagoya, Japan

\section{S. MIYAKE}

Shohzankai Medical

Foundation

Miyake Eye Hospital

Nagoya, Japan

H. MIYAZAWA

Dept. of Ophthalmology

Kobe University

Kobe, Japan

A.C.B. MOLTENO

Dept. of Ophthalmology

University of Otago

Dunedin, New Zealand

K.M. MONTEIRO DE CARVALHO

Dept. of Ophthalmology

State University of

Campinas

Sao Paulo, Brazil

\section{S. MORI}

Dept. of Ophthalmology

Sapporo Medical College

Sapporo, Japan

H. MORIZANE

2-10-1 Tamagawagakuen, Machida

Tokyo, Japan

K. MORIZANE

2-10-1 Tamagawagakuen

Machida

Tokyo, Japan
R. MORRIS

Moorfields Eye Hospital

London, U.K.

H. MUEHLENDYCK

Dept. of Strabismology and Neuroophthalmology University of Goettingen Goettingen, West Germany

A.D.N. MURRAY

Dept. of Ophthalmology

University of Cape Town

Cape Town, South Africa

T. NAKAGAWA

Dept. of Ophthalmology

Sapporo Medical College

Sapporo, Japan

P. NEMET

Dept. of Ophthalmology

Assaf Harofe Medical Center

Tel Aviv, Israel

E. NISHIDA

Dept. of Ophthalmology

Shiga University

Otsu, Japan

Y. NISHIDA

Dept. of Ophthalmology

Shiga University

Otsu, Japan

G.K. VON NOORDEN

Cullen Eye Institute

Baylor Coll. of Medicine

Houston, U.S.A.

K. NOMURA

Dept of Ophthalmology

Kobe Children's Hospital

Kobe, Japan 
xxii

N. NOZAKI

Dept. of Ophthalmology

Keio University

Tokyo, Japan

\section{Y. OGUCHI}

Dept. of Ophthalmology

Keio University

Tokyo, Japan

H. OHTSUKI

Dept. of Ophthalmology Okayama University

Okayama-shi, Japan

\section{T. OHZEKI}

Ohzeki Ophthalmic Clinic

Kanagawa-Ken, Japan

H. OKAYAMA

Dept. of Ophthalmology

Okayama University

Okayama-shi, Japan

\section{A.M. OLIVEIRA}

Dept. of Ophthalmology

University of Campinas

Sao Paulo, Brazil

T. OTORI

Dept. of Ophthalmology

Kinki University

Osaka, Japan

B. PATEL

Moorfields Eye Hospital

London, U.K.

L. A. PEDUTI-CUNHA

Dept. of Ophthalmology

University of Sao Paulo

Sao Paulo, Brazil
THE CONTRIBUTORS

V.L. PEREIRA

Dept. of Ophthalmology

State University of Campinas

Sao Paulo, Brazil

P.N. PLOWMAN

St. Bartholomew's Hospital

London, U.K.

\section{J.A. PRATT-JOHNSON}

Dept. of Ophthalmology

University of British

Columbia,Children's Hospital

Vancouver, Canada

\section{K.L. PRESTON}

Dept. of Ophthalmology

University of Washington

Washington, U.S.A.

E.L. RAAB

Dept. of Ophthalmology

Mount Sinai School of

Medicine

New York, U.S.A.

R.D. REINECKE

Wills Eye Hospital

Foerderer Eye Movement

Center for Children

Philadelphia, U.S.A

E. RINDZIUNSKI

University Eye Clinic

Rigshospitalet

Copenhagen, Denmark

M.R. RIVERS

The Royal Victorian

Eye and Ear Hospital

Melbourne, Australia

P.E. ROMANO

Gainesville, U.S.A. 


\author{
A.L. ROSENBAUM \\ Dept. of Ophthalmology \\ UCLA School of Medicine \\ Los Angeles, U.S.A. \\ P. ROSEN \\ Moorfields Eye Hospital \\ London, U.K.
}

\author{
M.S. RUTTUM \\ Dept. of Ophthalmology \\ Medical College of \\ Wisconsin \\ Milwaukee, U.S.A.
}

L. SAMUELSSON

Department of Orthopedic Surgery

Karolinska Institute

Stockholm, Sweden

C. SCHIAVI

Dept. of Ophthalmology

Modena University

Modena, Italy

C. SCHOR

School of Optometry University of California Berkeley, U.S.A.

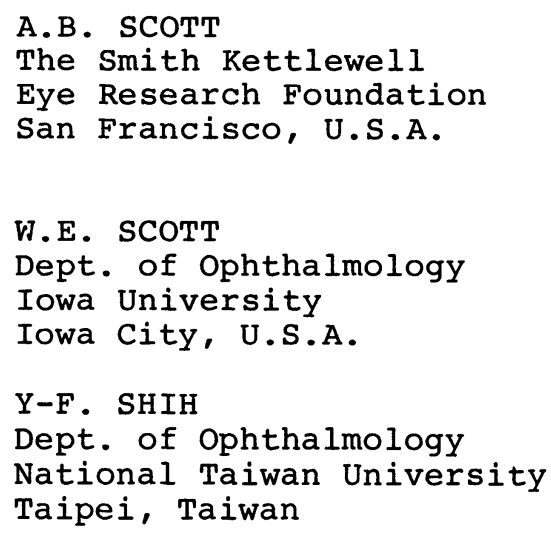

K.J. SHIMSHAK

Dept. of Ophthalmology

Medical College of Wisconsin

Milwaukee, U.S.A.

T. SHINKAI

Dept. of Ophthlmology

Shinkai clinic

Kobe, Japan

J.W. SHORE

Dept. of Ophthalmology

Harvard University

Boston, U.S.A.

J.T. SMITH

Dept. of Ophthalmology

Queen's University

Kingston, Canada

R.F. SPENCER

Dept. of Anatomy

Medical College of Virginia

Richmond, U.S.A.

A. SPIELMANN

11 Rue de la Ravinelle

Nancy, France

M. SPIRITUS

Dept. of Ophthalmology

Catholic University of

Louvain

Bruxelles, Belgium

D.R. STAGER

Dept. of Ophthalmology

Children's Medical Center

Dallas, U.S.A.

A. STARBUCK

Bristol Eye Hospital

Bristol, U.K. 
xxiv

H. STOLOVITCH

Dept. Ophthalmology

Tel Aviv University

Sackler School of Medicine

Tel Aviv, Israel

I. STRACHAN

Royal Hallamshire Hospital Sheffield, U.K.

N.T. STRANG

Royal Victorian

Eye and Ear Hospital

Melbourne, Australia

K. STROMLAND

Dept. of Ophthalmology University of Illinois

Chicago, U.S.A.

S. TAKAYAMA

Dept. of Ophthalmology

Kobe Children's Hospital

Kobe, Japan

M. TAKEDA

Mechanical System and

Technology Dept.

Mitsubishi Corp.

Amagasaki-shi, Japan

C. TAMBURELLI

Dept. of Ophthalmology

Catholic University

Rome, Italy

O. TAMURA

Dept. of Ophthalmology

Ehime University

Ehime, Japan

H. TANAKA

Dept. of Ophthalmology Osaka City University

Osaka, Japan
THE CONTRIBUTORS

J.N. TAYLOR

82 Collins street

Melbourne, Australia

Y. TSUKITA

Dept. of Ophthalmology

Kobe Children's Hospital

Kobe, Japan

K. TSUZUKI

Dept. of Ophthalmology

Nagoya University

Nagoya, Japan

Y. UEMURA

Dept. of Ophthalmology

Keio University

Tokyo, Japan

T. VINDING

University Eye Clinic

Ringshospitalet

Copenhagen, Denmark

J.W. WALKER

The Hospital for Sick

Children and

Moorfield Eye Hospital

London, U.K.

$\mathrm{A}-\mathrm{H}$. WANG

Dept. of Ophthalmology

National Taiwan University

Taipei, Taiwan

C. WANG

Dept. of Biomathematics

UCLA School of Medicine

Los Angeles, U.S.A.

Y. WATANABE

Dept. of Ophthalmology

Okayama University

Okayama-shi, Japan 
M. WATTS
Royal Hallamshire Hospital
Sheffield, U.K.

N.C. WHEELER

Dept. of Biomathematics UCLA School of Medicine Los Angeles, U.S.A.

I.M. WILLIAMS

Neuro-Opht ha lmology

Laboratory

Monash University

Melbourne, Australia

M.F. WILSON

Gainesville, U.S.A.

S.M. WOLFF

Wilmer Institute

The Johns Hopkins

University

Baltimore, U.S.A.

K.W. WRIGHT

Dept. of Ophthalmology

Children's Hospital

Los Angeles, U.S.A.

S-F. WU

Dept. of Ophthalmology

National Taiwan University

Taipei, Taiwan

K. WYBAR

Hill House

Aldeburgh

Suffolk, U.K.

T. YAGASAKI

Dept. of Ophthalmology

Nagoya University

Nagoya, Japan
R. YAMADA

Dept. of Ophthalmology

Keio University

Tokyo, Japan

S. YAMADA

Dept. of Ophthalmology

U.C.L.A. School of Medicine

Los Angeles, U.S.A.

M. YAMAMOTO

Dept. of Ophthalmology

Kobe University

Kobe, Japan

S. YARDE

Bristol Eye Hospital

Bristol, U.K.

T. YOKOYAMA

Dept. of Ophthalmology

Osaka City University

Osaka, Japan

J.J-H. YU

Dept. of Ophthalmology

National Taiwan University

Taipei, Taiwan

A.A. ZUBCOFF

Wills Eye Hospital

The Foerderer Eye Movements

Center for Children

Philadelphia, U.S.A. 


\section{The Linksz Award and Medal}

Past Recipients of the Linksz Award and Medal:

1978 Alfredo Arruga

1982 Robert Crone

1986 Alan B. Scott

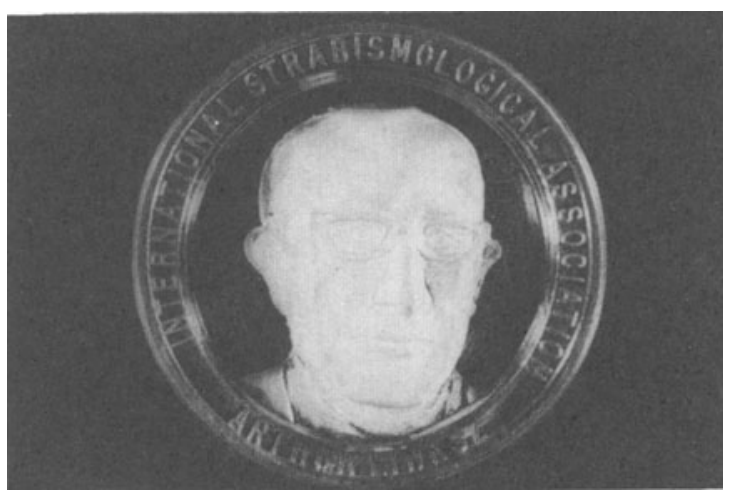

Arthur Linksz 
The 1990 Linksz Award and Medal was Presented to:

\section{ELFRIEDE AULHORN}

Professor Emeritus

Pathophysiology of Vision

University Eye Clinic

TÜBINGEN

Federal Republic of Germany

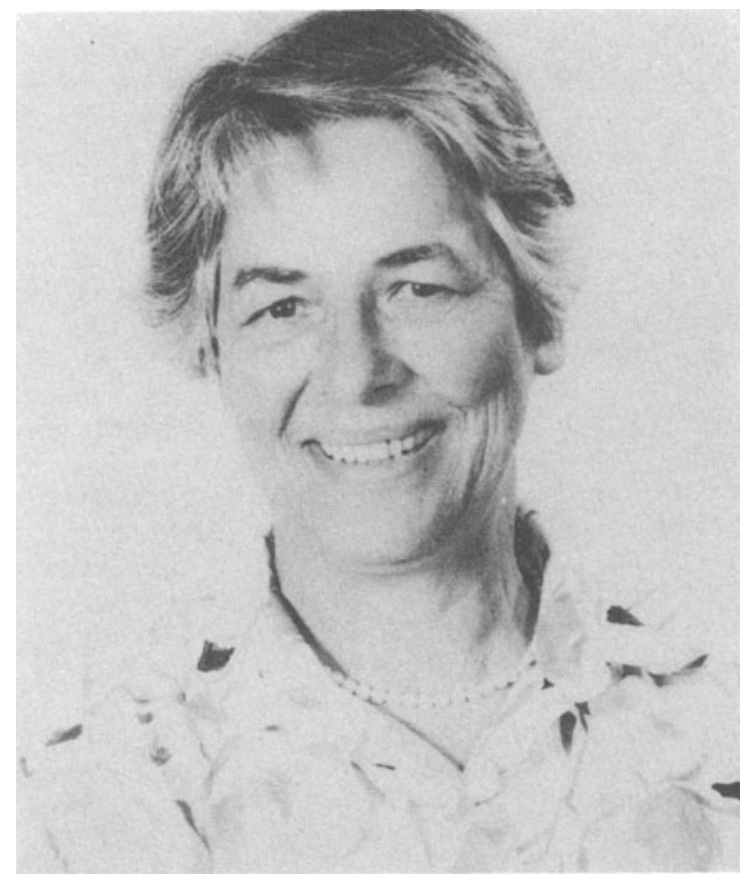

Elfriede Aulhorn 


\title{
Introduction of the Recipient of The Linksz Award and Medal: Elfriede Aulhorn
}

\author{
by Gunter K. von Noorden
}

The Linksz Award was donated in memory of Arthur Linksz by the Smith-Kettlewell Institute, in recognition of a scientist whose contributions has advanced our knowledge in the field of strabismus. This year's recipient is Prof. Elfriede Aulhorn, a member of our association, whose name is familiar to all of you.

Elfriede Aulhorn, after graduating from Medical School, began her scientific career at the Physiological Institute of the University of Goettingen in Germany. In 1954 she started her residency in ophthalmology at the University of Tuebingen where she rapidly advanced through the ranks and eventually became professor and director of the department for the Pathophysiology of Binocular Vision. She was eminently successful in analyzing the quantitative correlations between different visual functions, to perform such investigations under normal conditions of seeing and to apply this knowledge to the development of clinical testing procedures. Her enthusiasm for research and great originality has propelled her to the forefront of visual psychophysicists.

She was instrumental in developing the Tuebinger perimeter and the mesoptometer. Through her perimetric research we have learned about abnormal retinal sensitivity profiles in amblyopic eyes and the pathophysiology of eccentric fixation. Perhaps her major contribution pertaining to the field of strabismus, however, was the ingenuous design of the phase difference haploscope. With this instrument she has taught us about interocular inhibition in normal binocular vision and the spectrum of sensory disturbanres in amblyopia and suppression. 
I have had the good fortune of knowing Prof. Aulhorn for the past 30 years and ever since she generously offered us living quarters in her house during my postgraduate fellowship at the University of Tuebingen. Her great personal charm and warmth and her readiness to extend a helping hand make her a very special person. When I visited her a few months ago her house was brimming with refugees from Eastern Europe whom she had literally picked off the street to offer shelter. She told me then how much she was looking forward to receiving this award. Unfortunately and quite unexpectedly, however, she had to undergo a serious operation a few weeks ago which made it impossible for her to travel and has asked me to convey her gratitude to our organization for bestowing this honor upon her. 


\title{
OBITUARIES
}

\section{Thomas Keith Lyle (1904-1987)}

\author{
by Kenneth Wybar
}

Thomas Keith Lyle, who died on Saturday 9th, May, 1987, at the age of 83 years, was a distinguished ophthalmic surgeon who achieved an outstanding reputation in ophthalmology, particularly in strabismus.

He was educated at Dulwich College, London, Sidney Sussex College, Cambridge, and King's College Hospital, London, where he was the Burney Yeo Scholar. He was awarded the Todd Medal for clinical medicine. He became a Licentiate in Medicine and Surgery of the Society of Apothecaries in 1928, and it is interesting that, although he became a Bachelor of Medicine in 1930, he continued to the the LMSSA degree. This is almost certainly a reflection of his abiding love for the Worshipful Society of Apothecaries; he served on the Court for many years and became a highly regarded Master.

He became a Member of the Royal College of Physicians of London in 1930, and a Fellow of the Royal College of Surgeons of England in 1932. It was unusual at that time for an aspiring ophthalmic surgeon to obtain two such competitive higher qualifications in medicine and in surgery but his breadth of academic training is reflected in his interests in the problems of strabismus which reached out into the wider fields for medicine and neurology, rather than being confined to its sensory and motor complexities. He became a Master of Surgery in 1933, Doctor of Medicine in 1935, and Fellow of the Royal College of Physicians of London by election in 1963. He was created a Companion of the British Empire in 1963.

Keith Lyle was the son of an ophthalmic surgeon at King's College Hospital - Herbert Willoughby Lyle - who had been a physiologist in his earlier days, and subse- 
quently become Dean of the Medical School at King's college. It is fascinating to try and imagine the scene in the billiard room of Willoughby Lyle's house in Bromley many years ago when, on certain Saturday evenings, father, with a billiard-cue as a pointer, directed a wide range of questions on ophthalmology to Keith, his half-brother Eric Lyle and his cousin Geoffrey Cashell. This is an unusual use of a billiard-cue, but it may well have fostered Keith's outstanding ability to blend a deep knowledge of the theoretical aspects of a topic with a characteristically decisive approach!

Keith Lyle had little time for the junior who showed only a causal interest in ophthalmology, but there is a generation of juniors who are for ever grateful to him for the solid grounding which he provided in their formative years. He also had little time for ophthalmologists, particularly strabismologists, who created only fanciful theories, and he dismissed them as "hot air merchants."

In the years between 1929 and 1933 he was House Physician, House Surgeon, Senior Surgical Registrar and First Assistant in the Neurological Department at King's College Hospital. It is the mark of an outstanding student to be appointed to so many post-graduate appointments in his Teaching Hospital. Later he became House Surgeon at the Royal Westminster Ophthalmic Hospital (subsequently Moorfields Eye Hospital, High Holborn) which sealed his abiding interest in ophthalmology.

He served with the Royal Air Force Volunteer Reserve in World War II, from 1939 to 1946 and reached the rank of Air Commodore. He was also Consultant in Ophthalmology to the Royal Air Force overseas, and was mentioned in dispatches. He played a vital part in the war years in emphasizing the importance of the diagnostics and treatment of disorders of ocular motility in pilots at a time when combat skills were dependent largely on straight-forward visual accuracy. He continued his work with the Royal Air Force after the war as Civilian Consultant, and was also Civilian Consultant to the Ministry of Aviation.

Keith Lyle was Surgeon to Moorfields Eye Hospital, Ophthalmic Surgeon to King's College Hospital, and to the National Hospital for Nervous Diseases. He was Dean of the Institute of Ophthalmology at a time when postgraduate teaching in ophthalmology with large numbers of students from home and overseas was in a thriving phase. His skill and enthusiasm as Dean contributed greatly to the enhancement of the Institute and Moorsfield as cen- 
xxxii

ters of excellence.

He achieved many other recognitions: Examiner in Ophthalmology to the Royal College of Surgeons of England, and of Edinburgh; President of the Ophthalmological Society of the United Kingdom; President of the Faculty of Ophthalmologists; President of the Section on the United Services, and Vice-president of the Section of Ophthalmology of the Royal Society of Medicine; Founder Member and Vice-President of the Consilium Europaeum Strabismi Deditum - now the European Strabismological ASsociation; President of the International Strabismological Association; Member of the Orthoptic Board; and, Hospitaller to the Most Venerable Order of the Hospital of St. John of Jerusalem which was an appointment very close to his heart. He expended much time and effort in maintaining the excellence of St. John's Ophthalmic Hospital in Jerusalem which attracts patients from widespread areas of the Middle East, and on his retirement in 1980 he was honored by the distinction of a Knight Grand Cross.

Keith Lyle's interests in the problems of ocular motility formed a wide spectrum, but he had a special interest in the motor aspects of squint, particularly of an incomitant nature; this was fostered almost certainly by his exposure to many cases of trauma in the Royal Air Force in World War II, and subsequently by his long association with the National Hospital for Nervous Diseases. His interest in incomitant squint is highlighted by his emphasis on the necessity of a comprehensive preoperation assessment with a precise determination of the deviation (horizontal, vertical and torsional) in the cardinal positions of gaze and on near and distant fixation. It is also highlighted by his step-by-step approach to the surgical management of such cases in order to achieve a restoration of binocular fixation in the primary position and in as much as possible of the the binocular field of fixation. Sometimes this policy demanded a relatively minor final adjustment of one of the extrinsic ocular muscles, but this provided a longterm result which was out of all proportions to the trivial nature of the operation.

He contributed extensively over the whole of his working life to the journals, and he also wrote several textbooks. One of the early books - Practical Orthoptics in the Treatment of Squint - was published in 1937 with Sylvia Jackson, an orthoptist, which became the "bible" for orthoptic students in the United Kingdom and also many other countries. Keith Lyle asked me to collaborate in the production of the 5 th edition with the addition 
of several new chapters; it is poignant that some time before his death we were planning a new edition. He wrote the 8th edition of Worth and Chavasse's Squint, and subsequently he produced the 9 th edition in collaboration with Geoffrey Bridgeman. He also edited the 13 th edition of May and Worth's Diseases of the Eye with Alex Cross.

Keith Lyle gave several eponymous lectures - the Charles H. May Memorial Lecture in New York, the Doyne Memorial Lecture in Oxford and the Alexander Welch Lecture in Edinburgh. He was awarded the Nettleship Medal and the Richardson Cross Medal.

Keith Lyle was a man with vast intellectual abilities, with great clinical and surgical skills, and with an abundance of physical energy. I remember many years ago when Keith was Dean and I was Tutor at the Institute of ophthalmology we traveled together on many occasions in foot around lunch-time from the Institute of Ophthalmology in Judd Street to Moorfields Eye Hospital at High Holborn. The rate of progress set by Keith was prodigious, but this was much less startling than the route taken. He had a profound belief that the shortest distance between two points is a strait line, but its application in crossing Southhampton Row in a diagonal way at rush-hour raised certain doubts in my mind. However, there was never any mishap; whether this was due to Keith's speed or his sheer determination remains a mystery!

Keith Lyle married Jane Bouverie Maxwell in 1949, and they have three daughters and a son. For the greater part of their married life they lived at a charming house - Cherrycroft - in Oxfordshire. It was always a pleasure to visit their happy family home. 


\title{
Arthur Linksz (1900-1988)
}

\author{
by Gunter K. von Noorden
}

Arthur Linksz, one of the worid's authorities on color vision, physiological optics, binocular and space perception died March 19,1988, at the age of 87. Born in Hungary, he immigrated to the USA in 1939. He became a fellow and later an instructor at the famous Dartmouth Eye Institute in Hannover, New Hampshire, where he collaborated with Bielschowsky, Ogle, Herzau, Lancaster, Burian and Boeder. Later he moved to New York where he became Clinical Professor of Ophthalmology at New York University and New York Medical College and was engaged in private practice. He authored six books and numerous articles. An enthusiastic teacher with a keen and compassionate mind, Linksz held a lifelong interest in the arts, literature and humanities. He was a charter member of the I.S.A. and will be memorized through the Linksz Medal which is bestowed at each I.S.A. congress upon a scientist whose contributions have advanced our knowledge in the field of strabismus. 


\section{Charles Thomas (1906-1987)}

\section{by Annette Spielmann}

Professor Charles THOKAS unexpectedly died the $29^{\text {th }}$ of April 1987 at dawn after a heavy day of work. Indeed, still dynamic and enthusiastic at the age of 80 , he continued to practise his art privately in the same way as he did during his hospito-university career.

Born the $25^{\text {th }}$ of July 1906 in Avon, Professor THOMAS, student at the "Santé Militaire" school of Lyon, studied medicine in Nancy. His studies were brilliant: interne in 1929, "Chef de Clinique" of Ophthalmology in 1936, he was first "agrege" in 1939. He was only 33 and already Professor of Ophthalmology. In 1948, at the age of 42 , he became Head Professor of Ophthalmology.

Thanks to $\mathrm{hlm}$, the ophthalmological service of Hancy acquired a reputation which became more and more wide-spread. Mr. THOKAS was indeed one of the most skilful surgeons of his generation. He was one of the pioneers of the new techniques for cataracts, for glaucoma, for retinal detachment and mainly for corneal grafts. It was his initiative that led to the creation of the French Eye Bank in 1944 .

It was mainly a passion for strabismus that animated the life of this dynamic Chief of Service. His deep friendship with Professor Curt CüPPERS from Giessen was particularly productive. The scientific collaboration of these two masters of European Strabismology gave new momentum to research in strabismus and in amblyopia. Professor THOMAS created the Orthoptic Center of llancy and was the initiator of the French Certificate of Orthoptics. Thanks to him a new profession was born in France and lancy became a reknowned school of orthoptics. The department of orthoptics was not only limited to teaching, research and treatment, it was also the starting point for the prevention of functional amblyopia which practically disappeared in Lorralne.

It was not surprising that numerous well deserved honors were 
bestowed on such an extraordinary man. He was "Officler of the Legion d'Honneur", "Commandeur de l'Ordre National du Merite", "Commandeur de 1'Ordre des Palmes Academiques", "Chevalier de l'ardre de la Santé Publique". "Commandeur de l'Ordre Grand Ducal de la Couronne de Chêne de Luxembourg", et "Commandeur de l'Ordre du Million d'Eléphants et du parasol Blanc du Laos". Because of the exceptional value of his contribution to the development of orthoptics, he was Laureate of the Hational Academy of Medecine in 1965 and Corresponding Member in 1984. President and Founder of the European Strabismological Association during the days of Giessen in 1954, he was elected Vice-President of the International Strabismological Association the same year.

In his service, Mr. THOMAS was one of the "Kandarins" of his era. A relentless and indefatigable worker, he oversaw everything, demanding the same of athers as he did of himself and not understanding work badly done. Mr. THOKAS was certainly a Mandarin, but a Mandarin with a big heart. Heedful of the problems of all, avallable to both his patients and his students, he was firmly committed to the training and the promotion of his personnel.

He was a brilliant writer who sometimes wielded a pen "dipped in acid" when addressing letters to troublesome administrations whose rules he choose to challenge. This gift for writing, his brilliant and clear mind, his orational talent, was evident in his courses and conferences which were alway heavily attented. Mr. THOMAS was a highly appreciated teacher but he was above all a subtle clinician.

In his everyday life, Mr. THOMAS, a cultivated person, appreclated gastronomical pleasures and his boat on the Mediterranean. His vacations in Juan-Les-Pins were very dear to him. He spent all his, free moments with Mrs. THOMAS, his companion, to whom he was deeply attached. A devoted husband, he adored his daughter and his two grandchildren. How proud he must have been to be a great grandfather !

Mr. THOMAS conserved his passion for life, for his family and for his work until the last moment. He couldn't reconcile himself to abandoning his consultations nor his operations. At 80 years of age, he had a steady hand and a mind which has lost none of its intellectual qualities. He remalned full of curlosity, energy and humour: he was still young, that is the way his numerous patients saw him. It is in this way that we will remember this enthusiastic ophthalmolgist and strabismologist of great merit unhindered by age. 


\section{Tunekazu Yuge (1906-1987)}

\section{by Shinobu Awaya}

Dr. Tunekazu Yuge, Emeritus Professor of Kyoto Prefectural University of Medicine, who died December 18, 1987 at the age of 82 years, was an Honorary Member of the Japanese Ophthalmologica1 Society and the Honorary President of the Japanese Association of Strabismus and Amblyopia. He was a distinguished ophthalmologist, who made great contributions in many aspects of ophthalmology, particularly in strabismus and amblyopia.

He published many scientific papers and books on motor and sensory anomalies of strabismus. Through his books and lectures he introduced many of his unique concepts and appropriate technical terms, which he himself coined, in various fields of ophthalmology. He was a strict but warm-hearted teacher and educated many young ophthalmologists and orthoptists, who showed interest in strabismus and amblyopia, not only from his own department but also from many other departments at universities all over Japan. He was the head of the Organization which established the official status of the certified orthoptist in Japan.

He was the Session Chairman of the III Congress of the International Strabismological Association held in Kyoto in 1978. Those who attended this meeting always remember the great success of the meeting both in terms of scientific level and of organization which was in the hands of the Local Organizing Committee headed by Dr. Yuge.

In 1986, Dr. Yuge accepted honorary membership in the International Strabismological Association. It is with deep grief that our Association marks the passing of Dr. Yuge who was an outstanding strabismologist and great teacher and we shall always remember him with respect and affection. 